\title{
Lessons from LiDAR data use in the Netherlands
}

\author{
WILLEM BEEX, BEEX, Amsterdam, The Netherlands
}

\begin{abstract}
LIDAR provides data from which accurate models of the natural land surface completely stripped of buildings and vegetation can be derived. Interestingly for Cultural Heritage and Archaeology, most of the data is already freely available for research. This is certainly the case in the Netherlands, with the Actueel Hoogtemodel Nederland 2, or AHN2. The density of the measured points is at least 50 centimeters, which means that the remains of structures larger than one by one meter can be detected. As a result, many unknown structures have been discovered with it. However, these excellent results have blinded many Cultural Heritage and Archaeology practitioners to obvious mistakes when interpreting LiDAR data. This paper is intended to highlight best practices for the use of LiDAR data by Cultural Heritage professionals.
\end{abstract}

Key words:

LIDAR, DEM, New Archaeological Finds

SDH Reference:

Willem Beex 2017. Lessons from LiDAR data use in the Netherlands. SDH, 1, 2, 661-670.

DOI : $10.14434 /$ sdh.v1i2.23270

\section{INTRODUCTION}

LiDAR is an acronym for Light Detection and Ranging or, alternatively, Laser Imaging Detection and Ranging. Modern LiDAR data sets are often freely available via the internet. For instance, in the Netherlands the Actueel Hoogtemodel Nederland (AHN) website makes available the most recent Digital Elevation Model (DEM) of the country (ahn arcqisonline.nl/ahnviewer/). Many other European countries have similar services.

Modern LiDAR data offer a unique opportunity to detect previously undocumented surface cultural heritage (Hesse 2010.]. These data are often presented using excellent software applications, which are capable of creating beautiful images very easily. In particular, the possibility to "see beneath the vegetation" is highly appreciated. Its use has produced several important and interesting woodland discoveries in recent years [Creemers et al. 2011; Bazelmans 2016; van der Schriek 2016; Meylemans et al. 2016].

However, there are several important caveats that must be considered:

i. most LiDAR data are not as uniformly distributed as expected;

ii. automatic and semi-automatic classification of point data is never $100 \%$ perfect;

iii. the maximum guaranteed density of measured points determines the minimum size of features that can be detected;

iv. gridding algorithms have limitations; and

Author's address: Willem Beex, Beex, Blankenstraat 172, 1018 SG Amsterdam, The Netherlands; email: info@beex.nl Permission to make digital or hardcopies of part or all of this work is granted without fee according to the open access policy of SDH.

(C) 2017 SDH Open Access Journal

Studies in Digital Heritage, Vol. 1, No. 2, Publication date: December 2017 
v. the results are often presented in such a beautiful way by modern applications that the need for field validation of the results is sometimes neglected.

The aim of this paper is not only to consider these problems, but also to provide a checklist that scholars can use in applying LiDAR data to their research.

\section{GAPS IN THE DATA}

It can be useful to consider RADAR when studying LiDAR, as the two work in a similar manner. As with RADAR, a LiDAR beam will reflect off the first object in its path. This object is what gives a "return" and it also leaves a "shadow" behind it. It is very important to understand this, as it means that LiDAR can only create a dense and smooth model of the actual surface if enough laser beams can reach the ground level [Gatziolis and Andersen 2008].

In order to optimise the results, all LiDAR flights in the Netherlands take place during the winter months, December 1 through March 31 [Heerd et al. 2000; van der Zon 2015]. This is the best period of the year for "seeing through the forest" as deciduous trees have shed their leaves and not yet grown new ones.

Taking advantage of the winter period will obviously not work for coniferous forests. So, what is visible from the air will entirely depend on the number of viewpoints and the density of the canopy. Thus, a uniform distribution will rarely occur, as parts of the surface will not be reached by the laser [van der Zon 2015]. For this reason, it is very important to investigate the actual point-cloud provided by the organization that took the measurements. All competent organizations will have this data available for research. For example, on the Dutch AHN2 website all point-clouds are available for download. It is even possible to download special GeoTIFF images that mask the areas with a substandard number of observations [van der Zon 2015].

However, for a detailed analysis it is often better to visualize the point-cloud projected onto a map of the research area. Several applications exist, both commercial and freeware, which are capable of this operation. Usually it is best to get the program, or additional module, that can be incorporated into the existing workflow. When choosing software, it is wise to remember that LiDAR point-clouds contain huge numbers of individual measurements. It can therefore be worthwhile augmenting the internal memory (RAM) of the computer and it is wise to test the applications with the available hardware and operating system configuration.

An example from the LiDAR point-cloud of the Dutch coniferous forest near Wolfheze, shows exactly what should be considered before any further analysis (fig. 1). The points on the surface, indicated by yellow spheres for better visibility, are clearly not uniformly distributed. The vegetation, shown by the green dots, obstructed the laser in many places.

This means that only larger features, like ditches and trenches, will consistently appear in the 3Dmodels of an area, while smaller objects, like barrows, may not be detected. More deceptively, the untrained observer of a fully processed visualization based on LiDAR data may get the impression that the area has been disturbed. Knowledge of the actual point-cloud should help avoid this kind of misinterpretation. 


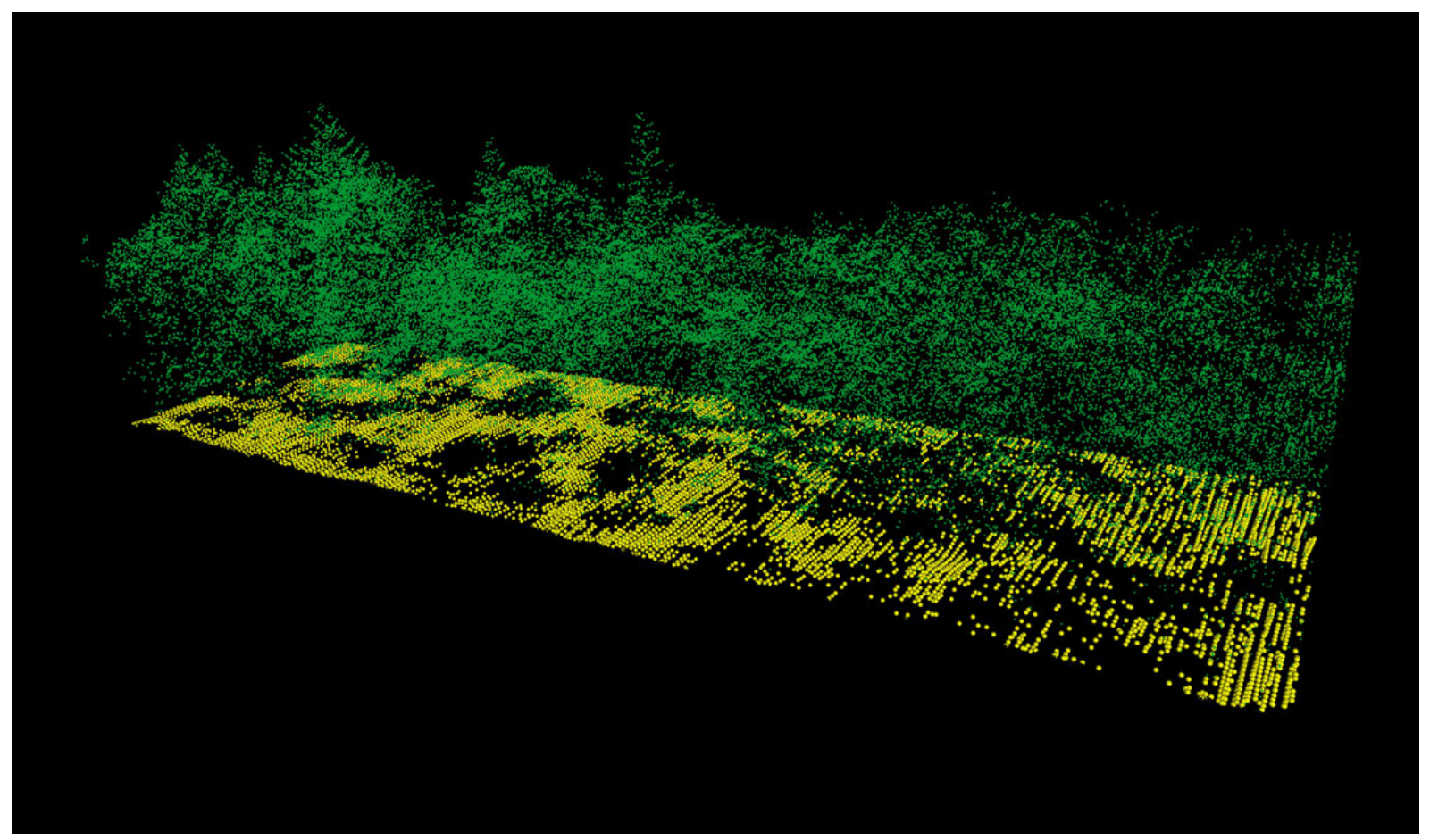

Figure 1. Coniferous forest near Wolfheze. Point-cloud of the ground in yellow and of the vegetation in green. The gaps on the ground, created by the trees, are clearly visible.

\section{CLASSIFICATION OF THE DATA}

Most modern LiDAR data are available in one or more files representing a classification [van der Zon 2015]. This classification is mainly based on "laser returns." This principle is based on the fact that a pulse (or "laser return") will receive the reflection from the top of a tree or a building slightly earlier than from halfway down a tree or a building, or from the actual ground surface. Other variables, like the intensity of the reflection of different kinds of materials, are also detectable [Berendsen and Volleberg 2007; English Heritage 2010].

Using a (semi-)automatic method, it is possible to classify each measurement based on all those tiny differences. In its most elaborate configuration, a LiDAR file can have points classified with one of up to 31 definitions [Gatziolis and Andersen 2008]. However, usually only eight such classes will be used, mainly to differentiate between levels in vegetation, buildings, water, ground, and unclassified data.

The Dutch AHN2 uses a slightly different approach. Here the main division is between surface- and other measurements. This is because it is primarily intended for water management [van der Zon 2015].

In general, LiDAR classification is an excellent approach. However, it is important to remember that LiDAR classification is never $100 \%$ perfect [van der Zon 2015]. It is still a semi-automatic process. This 
means that the software will not detect all the differences, so manual editing may be necessary. The definition of features, certainly in Cultural Heritage, can also be problematic. For instance, what should be done about the remains of earthworks; are they part of the ground, or are they part of a structure?

A very good example can be given from the Kempen region in the Dutch Province of Noord-Brabant. For undocumented reasons, two similar restored Bronze Age barrows have been classified in different ways. Figure 2 clearly shows that one barrow (on the left) with its ring-shaped wall, has been removed from the surface-data. It was identified as a man-made addition, even though the adjacent barrow was left in the surface data. In addition, another similar structure five kilometers away (on the right) was also left as part of the surface-data.

In these cases it was easy for researchers to spot these differences. However, it illustrates the danger of blindly accepting LiDAR classification without any further checks.

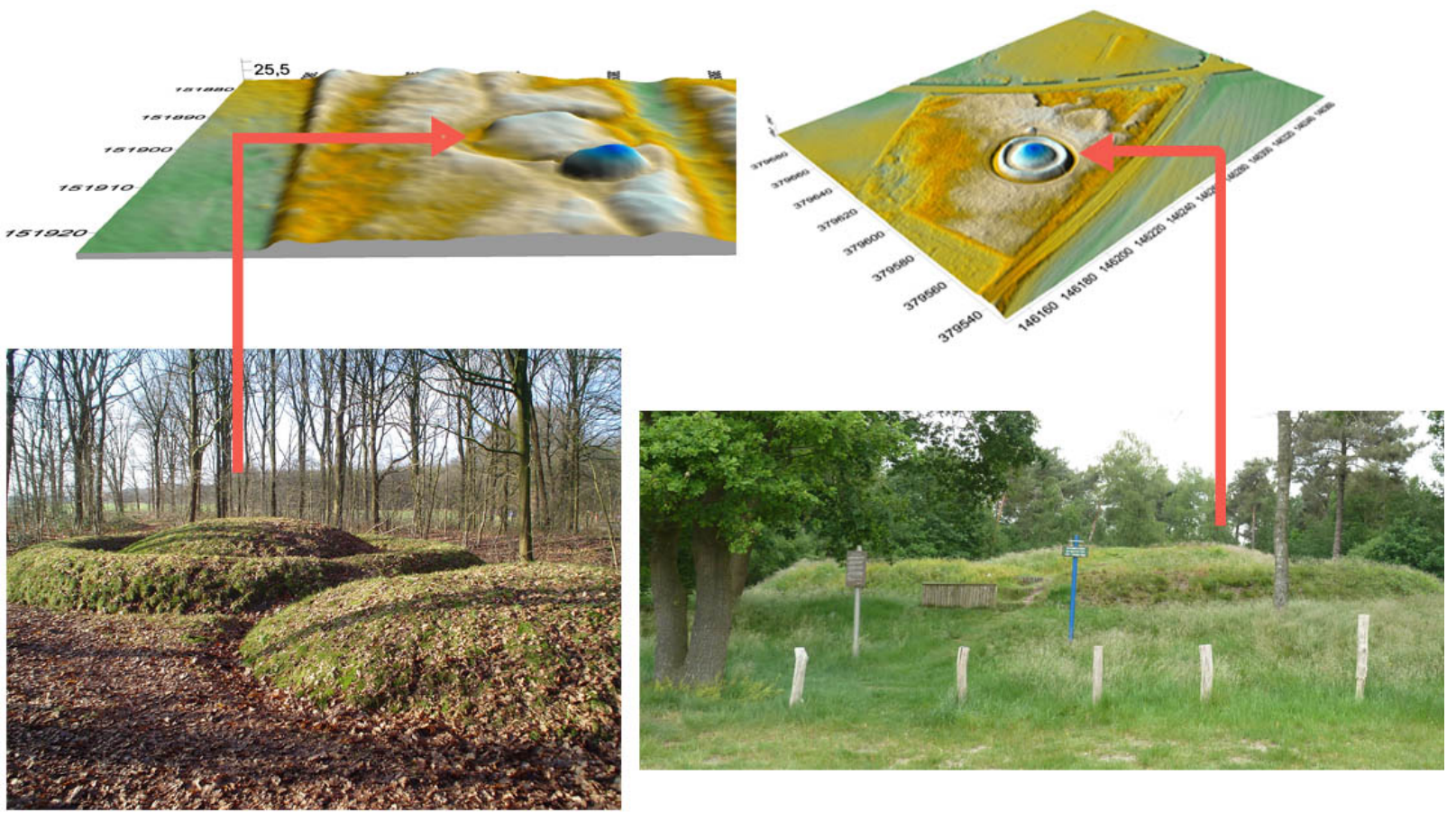

Figure 2. Three similar Bronze Age barrows in the Kempen region, Dutch province of North-Brabant. For some undocumented reason the barrow and the ring-wall on the left have been removed in the classified LiDAR data, but the other two remain. The site on the left is Toterfout - Halve Mijl, Zand-Oerle. The barrow on the right is Den Zwartenberg in Hoogeloon. The co-ordinates follow the Dutch New Amersfoort RD projection. 


\section{DENSITY OF THE DATA VERSUS DETECTED FEATURES}

While modern LiDAR sources like AHN2 have improved sampling density over earlier surveys, there is still a minimum size of feature that can be detected. It is wise to remember that even this improved sampling density can be effectively degraded by vegetation cover, like coniferous forests. The Nyquist-Shannon Sampling Theorem can be used to determine the size of feature that can be detected with any specific sampling spacing. The feature size detection threshold is an area twice the sampling distance in each direction, and a recognizable shape can only be found when the area of the feature is five times the sampling distance in each dimension [Beex 2003]. This means that if your LiDAR data-set has a point every meter, only features with a minimum size of two by two meters will be reliably detected and only features with a minimum size of five by five meters will have the correct shape.

A comparison between the older Dutch AHN1 data and the new AHN2 measurements clearly shows this. AHN1 guaranteed a five-meter resolution and AHN2 a 50-centimeter resolution. Figure 3 shows part of the Maas-Ruhr-Stellung (The Meuse-Ruhr Defence line), the German defences on the east bank of the river Meuse, dating from late 1944 and early 1945 [Seltmann 2006; van der Schriek and Beex 2017]. This elaborate trench-system is barely discernible on the AHN1 image but much finer detail is visible on the AHN2 derived image.
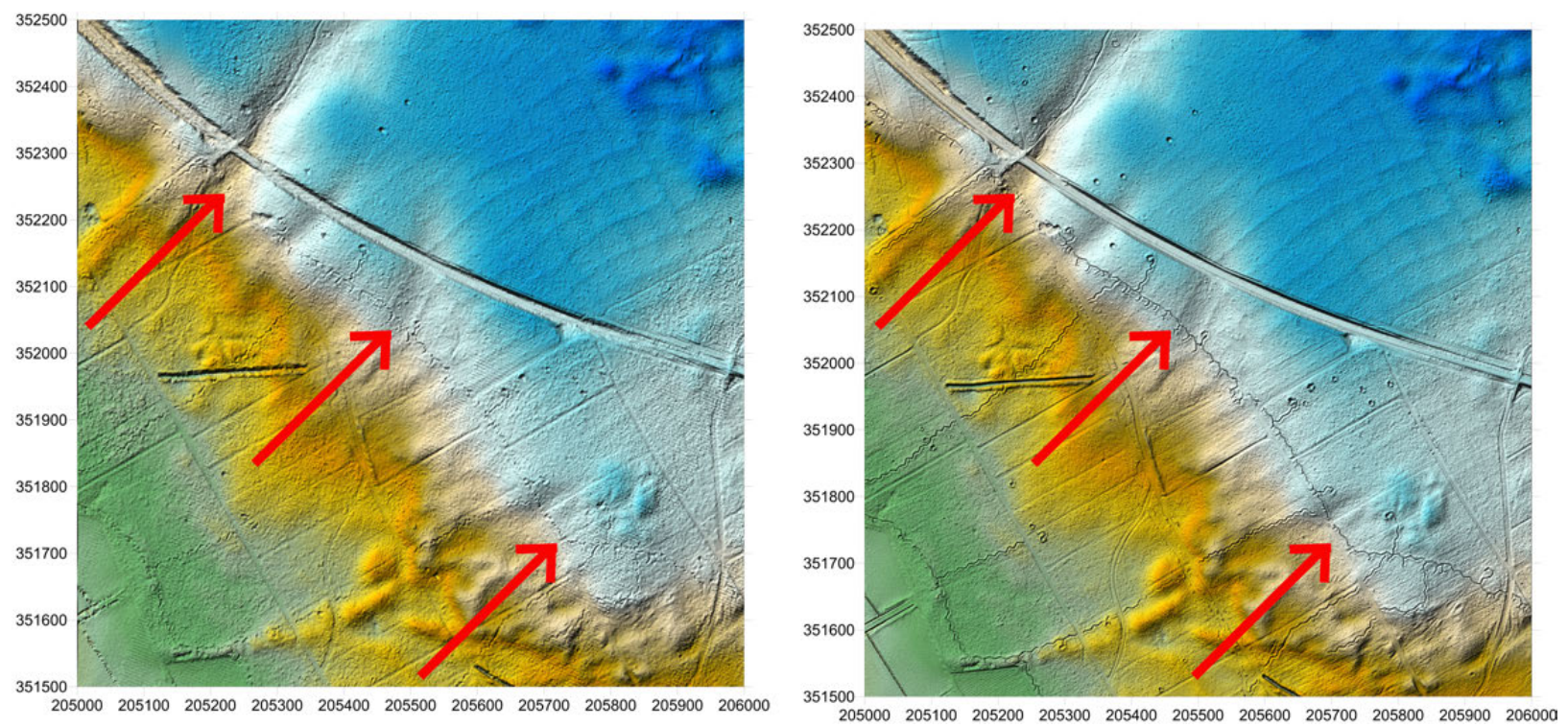

Figure 3. Differences in quality between the older Dutch AHN1 on the left, and the newer Dutch AHN2 on the right. The red arrows indicate the remains of the German "Maas-Ruhr-Stellung" (The Meuse-Ruhr Defence line). In the higher blue area, the remains of a 'Celtic Field' system are also visible. The co-ordinates follow the Dutch New Amersfoort RD projection.

The obvious conclusion is that LiDAR-data should not be used to visualise anything smaller than the detection threshold. However, with powerful modern computers it can be tempting to use lower detection thresholds. Indeed, it is often the case that students try a lower detection threshold value, 
as it gives a 'sharper look' to the visualization. Such behavior will not only create false algorithmic artefacts but also gives a deceptive illusion of precision. This in turn may deceive other researchers, who may then draw incorrect conclusions. Thus, despite the temptation, this practice should be avoided.

\section{ALGORITHMS}

It is often forgotten that any LiDAR-map or 3D-model is in fact the output of an algorithm. Even with a dense network of measurement points, translation into a mesh or a contour map must still occur. This is a sophisticated operation for which many alternative mathematical solutions are available.
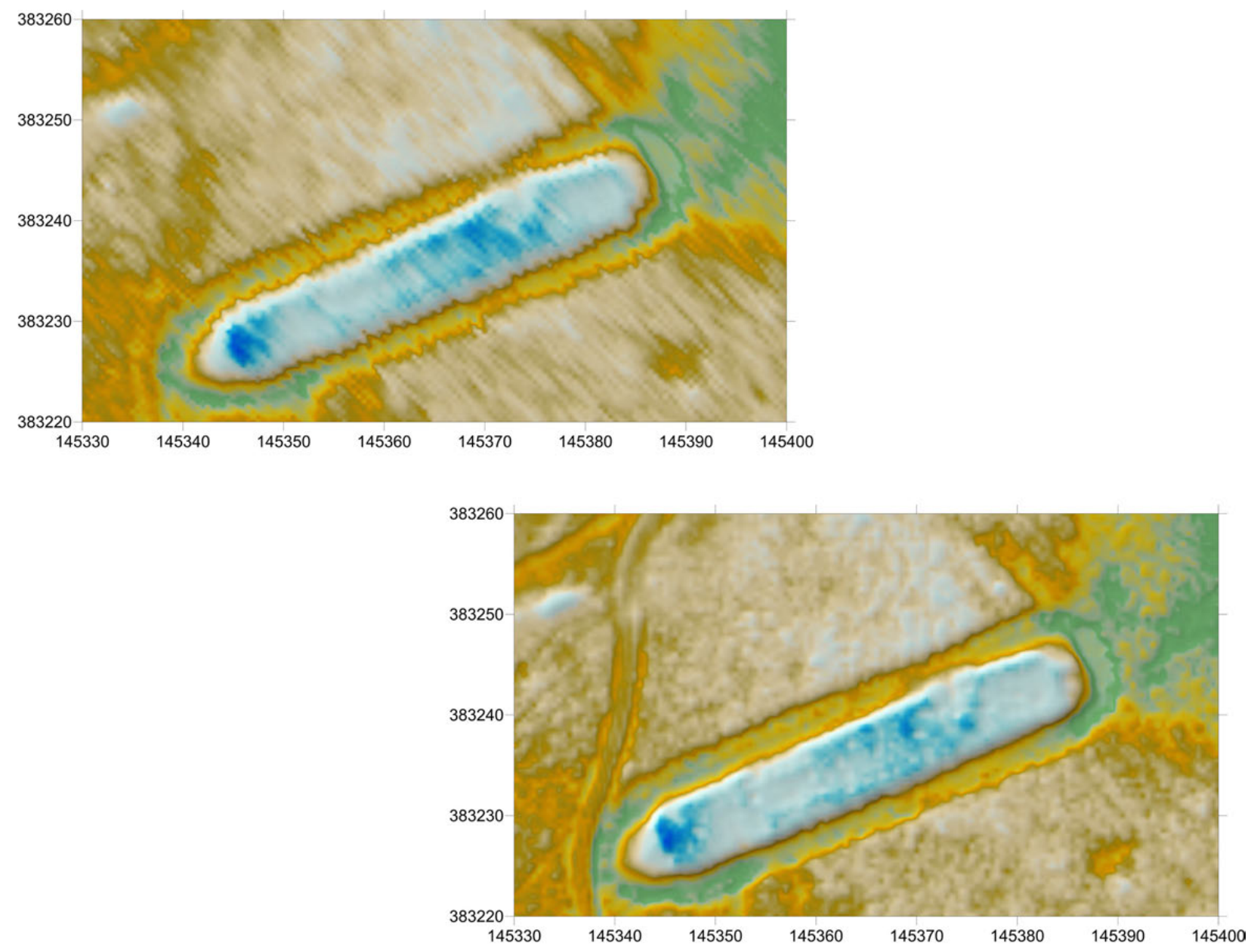

Figure 4. Two very different images of the same LiDAR data. Both images show the same earthwork representing a model of a British WWII convoy ship. But in the top left picture, the algorithm especially searched for small ditches running NW-SE. Used in this way, it almost looks as if the site has been recently ploughed. In this case, the bottom-right image with a basic search gives a more accurate representation of the earthwork. The co-ordinates follow the Dutch New Amersfoort RD projection. 
Two very different results from the same area near Westelbeers, The Netherlands, clearly show the implications of using different algorithms (fig. 4). The images show an earthwork built to represent a British WWII convoy ship. The site was used for target practice by German StuKa dive bombers [Beex 2009; van der Schriek 2016].

Both images were created with the same LiDAR data-points. In fact, even the basic algorithm used was the same; Kriging with a 5 by 5 metre search-radius [Cressie 1990; Abramowitz and Stegun 1972; Surfer 13 2016]. However, in the top left image, the algorithm was configured to look for elongated structures running NW-SE. As a result, the same data is processed in a different manner, and the resulting image looks as if the site has been ploughed.

This example clearly shows that the operator must be careful. The computer does not know the difference, so the researcher must use his/her expertise to select the appropriate method. For instance, some algorithms are particularly adept at finding specific shapes in the landscape, such as linear features like ditches or walls, but can also produce distorted images or 3D-models with false structures in them.

First, the researcher needs to have an understanding of the distribution of the original measurements, the actual landscape, and the physical nature (size and shape) of the features that are under investigation. Second, proper knowledge of the limitations of the available algorithms is required [Beex 2003]. If these conditions are not met, any result is in fact doubtful.

\section{ALWAYS CHECK THE RESULTS IN THE FIELD}

An actual inspection of the research area may seem obvious, but cannot be emphasized too often. For example, only a survey of the terrain of the earthworks near Westelbeers clearly showed why the four structures could be detected by LiDAR, whereas the fifth had completely vanished (fig. 5) [Beex 2009; van der Schriek 2016].

The fifth ship was built on a heath that has since become arable land. Its location was outside the area designated as a nature reserve during the 1950's. It was subsequently removed, along with the topsoil, as part of agricultural development. This meant there was no elevation remaining to be measured.

The fourth model, while located on the heath and within the nature reserve, was in an area of fastgrowing vegetation (fig. 5/4). Therefore, it was not detected when the other three earthworks were restored a decade ago.

Of course, there were also other contributing factors. Conflict Archaeology was still in its infancy [Van der Schriek and Van der Schriek 2014], so no proper archaeological survey was conducted at the time of restoration. The area was a restricted military complex during the war and so not many people knew about the structures.

In any case, this example clearly shows the need for background information and actual inspection of the terrain. Without this knowledge, conclusions could have been very wrong indeed. 


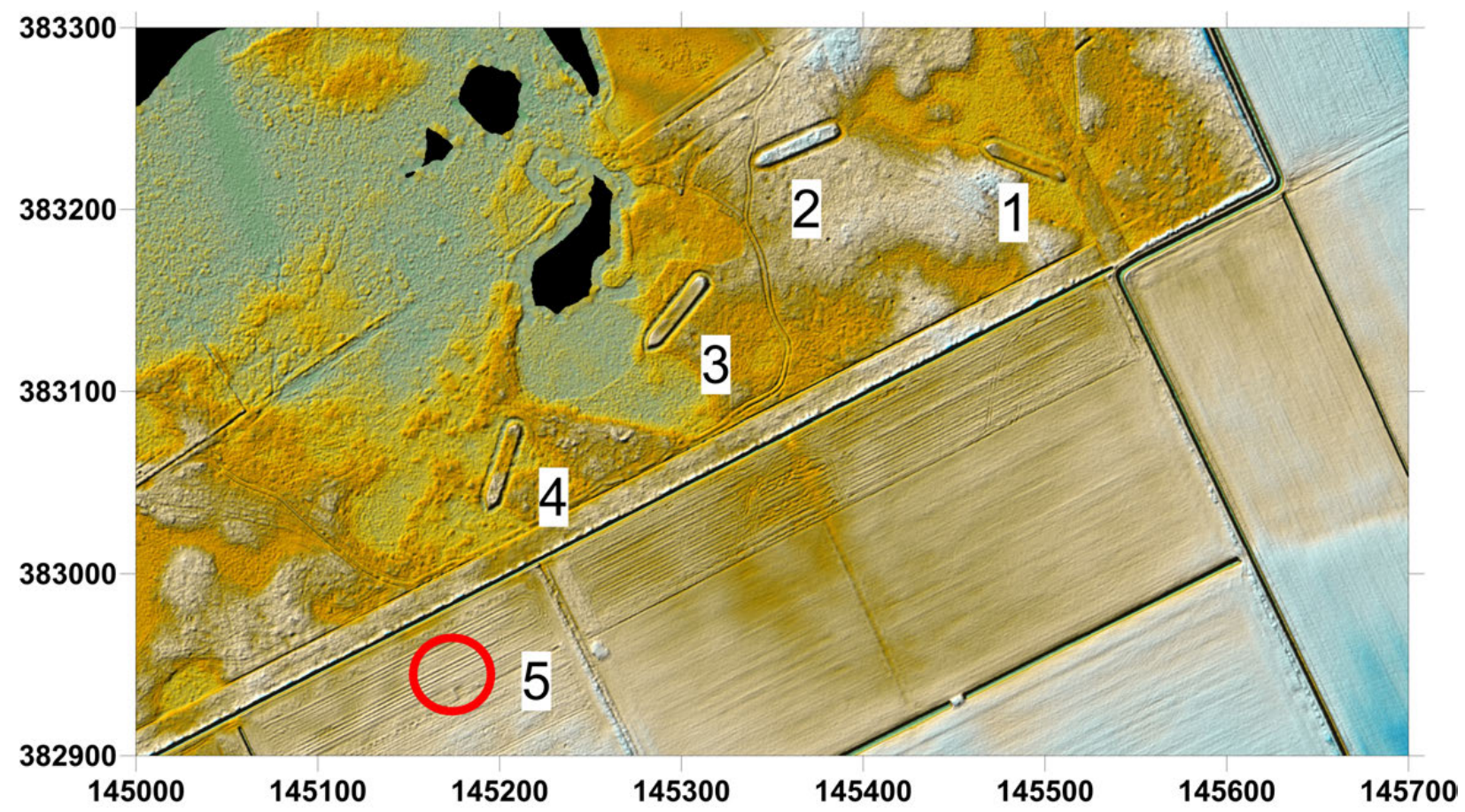

Figure 5. Location of earthworks (1-4) representing a British WWII convoy near Westelbeers (Province of NoordBrabant, The Netherlands.) used for target-practice by German StuKa bombers. The red circle indicates the spot where a fifth earthwork used to be. The co-ordinates follow the Dutch New Amersfoort RD projection.

\section{CONCLUSION}

If taken for granted, even the most beautiful LiDAR-images can become a source of incorrect interpretations and future mistakes. There are five important aspects of LiDAR-data that should always be checked and validated, before further analysis is undertaken. Perhaps the best solution would be to add an additional map with each LiDAR-image, showing the quality of the individual fields in the documented area. But at least metadata, or a very good description of the entire process, must be available, even if the maps and models are prepared by another institution.

\section{A HELPFUL CHECKLIST}

Researchers working with LiDAR-data should consider these five points:

- Always check for the presence of gaps in the data.

- Always check the classification of the data.

- Always check the density of the data versus the size of the detected features.

- Always check which algorithms and variables were used.

- Always ground-truth the results in the field. 


\section{ACKNOWLEDGEMENTS}

The author would like to thank Max van der Schriek, PhD researcher at the Vrije Universiteit, for the Dutch WWII examples, and Bert Brouwenstijn, Vrije Universiteit, for the poster design.

\section{REFERENCES}

M. Abramowitz and I. Stegun. 1972. Handbook of Mathematical Functions. New York: Dover Publications.

J. Bazelmans. 2016. Het AHN2 en het raadsel van het toponiem Bussum-Fransche Kamp. Archeologica Naerdincklant. Archeologisch tijdschrift voor het Gooi en omstreken 1, 11-23. Available at: https://independent.academia.edu/Naerdincklant

B. Beex. 2009. Oefenbommen op een zee van heide. Vitruvius 9: 18-21.

W. Beex. 2003. Use and Abuse of Digital Terrain/Elevation Models. Enter the Past. The E-way into the Four Dimensions of Cultural Heritage. CAA 2003. Computer Applications and Quantitative Methods in Archaeology. BAR International Series, 1227.

H. J. A. Berendsen and K. P. Volleberg. 2007. New prospects in geomorphological and geological mapping of the Rhine-Meuse Delta - Application of detailed digital elevation maps based on laser altimetry. Netherlands Journal of Geosciences. Geologie en Mijnbouw 86(1):1:D. 15-22.

G. Creemers et al. 2011. Laseraltimetrie en de kartering van Celtic Fields in de Belgische Kempen: mogelijkheden en toekomstperspectieven. Relicta, 7: 11-36.

N. A. C. Cressie. 1990. The Origins of Kriging. Mathematical Geology 22: 239-252.

English Heritage, 2010. The Light Fantastic. Using airborne lidar in archaeological survey. Swindon.

D. Gatziolis and H. E. Andersen. 2008. A Guide to LiDAR Data Acquisition and Processing for the Forests of the Pacific Northwest. United States Department of Agriculture. [online] [Accessed 15 November 2016]. Available at: http://www.fs.fed.us/pnw/pubs/pnw_gtr768.pdf

R. M. van Heerd et al. 2000. Productspecificatie AHN 2000. Rijkswaterstaat: Rapportnummer: MDTGM 2000.13

R. Hesse. LiDAR-derived Local Relief Models - a new tool for archaeological prospection. Archaeological Prospection 17: 67-72.

E. Meylemans et al. 2016. Revealing extensive Protohistoric Field Systems through high resolution LiDAR data in the Northern part of Belgium. Archäologisches Korrespondenzblatt 45(2): 1-17.

M. van der Schriek. 2016. Dutch Military Landscapes. Heritage and Archaeology on WWII conflict sites. $20^{\text {th }}$ Conference on Cultural Heritage and New Technologies, Vienna (CHNT20). Available at: http://www.chnt.at/wp-content/uploads/eBook_CHNT20_vanderSchriek_2015.pdf

J. van der Schriek and M. van der Schriek. 2014. Metal Detecting: Friend or Foe of Conflict Archaeology? Investigation, Preservation and Destruction on WWII sites in The Netherlands. Journal of Community Archaeology and Heritage 1.3, pp. 228-244.

M. van der Schriek and W.F.M. Beex. 2017. The application of LiDAR-based DEMs on WWII conflict sites in the Netherlands. Accepted for publication on the Journal of Conflict Archaeology.

M. van der Schriek. 2017. Archaeological Research and Heritage Management on Second World War conflict sites in the Netherlands. Accepted for publication on the Journal of Conflict Archaeology. 
M. Seltmann. 2006. Die Maas-Rur-Steilhang-Elmpter-Wald-Stellung (Steuben-VolkerSchenkendorf-Stellung). Profil-Bauwerke-Geschichte. Eine Bestandsaufnahme. Mönchengladbach, März. [online] [Accessed 16 January 2017] Available at: http://7grad.org/Exkursionen/Westwall/Maas-Rur/maas-rur.html

Surfer 13. 2016. User's Guide. Powerful Contouring, Gridding, and Surface Mapping. [online] [Accessed 16 January 2017]. Available at:

http://downloads.goldensoftware.com/guides/Surfer12_Users_Guide_Preview.pdf

A. T. Wijnen et al. Conflict Archaeology in the Netherlands: The Role of Communities in an Emerging Archaeological Discipline. Journal of Community Archaeology and Heritage, 3(1): 2239.

N. van der Zon. 2015. Kwaliteitsdocument AHN2. Actueel Hoogtebestand Nederland. [Accessed 13 October 2016] Available at: http://www.ahn.nl/binaries/content/assets/hwh--ahn/common/wat+is+het+ahn/kwaliteitsdocument_ahn_versie_1_3.pdf

Received March 2017; revised July 2017; accepted August 2017. 